CZASOPISMO INŻYNIERII LĄDOWEJ, ŚRODOWISKA I ARCHITEKTURY JOURNAL OF CIVIL ENGINEERING, ENVIRONMENT AND ARCHITECTURE

JCEEA, t. XXXIII, z. 63 (4/16), październik-grudzień 2016, s. 565-572

\author{
Michał WICHLIŃSKI ${ }^{1}$ \\ Rafał KOBYEECKI ${ }^{2}$ \\ Zbigniew BIS ${ }^{3}$
}

\title{
BADANIA ZAWARTOŚCI RTĘCI W PŁYTACH GIPSOWO-KARTONOWYCH I GIPSACH
}

\begin{abstract}
W artykule przedstawiono wyniki badań zawartości rtęci w płytach gipsowokartonowych wykorzystywanych $\mathrm{w}$ budownictwie. Celem pracy jest zwrócenie uwagi na problem jakim jest bardzo duża koncentracja rtęci w w/w płytach, które są powszechnie stosowane w budownictwie. Płyty gipsowo-kartonowe są obecnie najpopularniejszym materiałem od wykańczania pomieszczeń w tzw. suchej zabudowie. Gips zawarty w tychże płytach pochodzi głównie z instalacji mokrego odsiarczania spalin (IOS) i jako taki jest obarczony ładunkiem rtęci, który został usunięty ze strumienia spalin w IOSie. Do badań wykorzystano 4 płyty gipsowokartonowe, różnych producentów, zakupione w marketach budowlanych w Częstochowie, oraz dwie próbki gipsu budowlanego. Wyniki badań zawartości rtęci przeprowadzono przy, użyciu spektrometru Lumex RA-915+ z przystawką pirolityczną RA-91C. Uzyskane wyniki pokazują, że średnia zawartość rtęci w płytach jest na bardzo wysokim poziomie i wynosiła od 227 do $458 \mathrm{ng} / \mathrm{g}$. Zawartość rtęci w gipsie budowlanym wynosiła od 57 do $305 \mathrm{ng} / \mathrm{g}$. Przeprowadzono także badania polegające na poddaniu wycinka płyty działaniu temperatury. Wycinek płyty ogrzewano ze stałą szybkością, jednocześnie mierząc ilość uwolnionej rtęci. Wyniki pokazały, że emisja rtęci następowała w temperaturach od 150 do $300^{\circ} \mathrm{C}$, przy czym maksima emisji były w temperaturach 190 i $270^{\circ} \mathrm{C}$. Taka temperatura uwalniania rtęci świadczy, że rtęć zawarta w płytach gipsowo-kartonowych jest głównie w związku HgS.
\end{abstract}

Słowa kluczowe: płyty gipsowo-kartonowe, gips, budownictwo, mokra instalacja odsiarczania spalin

${ }^{1}$ Autor do korespondencji / corresponding author: Michał Wichliński, Politechnika Częstochowska, Katedra Inżynierii Energii, ul. Brzeźnicka 60a, 42-200 Częstochowa; tel. 34 3250118; michal.wichlinski@gmail.com

${ }^{2}$ Rafał Kobyłecki, Politechnika Częstochowska, Katedra Inżynierii Energii, ul. Brzeźnicka 60a, 42-200 Częstochowa; tel. 34 3250118; rafalk@is.pcz.czest.pl

3 Zbigniew Bis, Politechnika Częstochowska, Katedra Inżynierii Energii, ul. Brzeźnicka 60a, 42-200 Częstochowa; tel. 34 3250118; zbis@is.pcz.czest.pl 


\section{Wprowadzenie}

Emisja dwutlenku siarki do atmosfery jest wciąż jednym z największych problemów energetyki. Oprócz problemów z samą emisją, problem stanowi również korozja powierzchni grzewczych kotłów energetycznych. Siarka zawarta w węglu jest emitowana do atmosfery głównie jako dwutlenek siarki $\left(\mathrm{SO}_{2}\right)$ i w niewielkiej ilości, od 0,5 do 3\%, jako trójtlenek siarki $\left(\mathrm{SO}_{3}\right)$ [1]. Pozostałe związki siarki mogące występować w spalinach mają marginalne znaczenie [1]. Polskie węgle zawierają od 0,5 do $4,5 \%$ siarki elementarnej. Jednakże węgiel dostarczany do elektrowni zazwyczaj zawiera około 1,5\% siarki. Elektrownia spalająca węgiel kamienny emituje od 1 do $8 \mathrm{~g} \mathrm{SO}_{2} / \mathrm{m}^{3}$, natomiast spalająca węgiel brunatny około $2,7 \mathrm{~g} \mathrm{SO}_{2} / \mathrm{m}^{3}$ [2]. Całkowita emisja $\mathrm{SO}_{2}$ w Polsce od roku 2000 do 2014 systematycznie się zmniejsza. W roku 2000 wyemitowano w Polsce około 780 tys. t, a w roku 2014 już tylko 277 tys. t, co oznacza spadek o około $65 \%$ na przestrzeni 14 lat (rys. 1) [3].

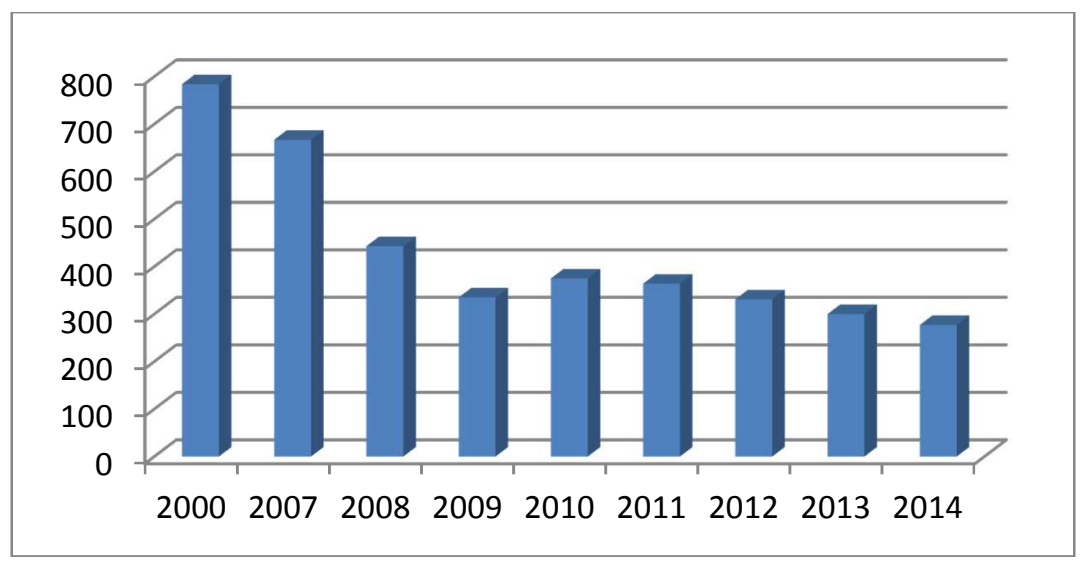

Rys. 1. Emisja dwutlenku siarki z energetyki zawodowej w Polsce w latach 2000-2014 na podstawie [3]

Fig. 1. Emission of sulfur dioxide from polish power plants in years 2000-2014 based on [3]

Najczęściej wykorzystywaną metodą odsiarczania spalin jest mokra metoda wapienna, która jest stosowana na całym świecie. Metoda ta znalazła również powszechne zastosowanie w polskiej energetyce, gdzie jest stosowana praktycznie w większości dużych bloków energetycznych wykorzystujących kotły pyłowe, zarówno tych opalanych węglem kamiennym, jak i brunatnym. Mokra metoda wapienna polega na przemywaniu spalin wodną zawiesiną mleka wapiennego $\left(\mathrm{CaOH}_{2}\right)$, lub wodną zawiesiną kamienia wapiennego $\left(\mathrm{CaCO}_{3}\right)$ [2]. Zaletami tej metody są niskie koszty inwestycyjne i eksploatacyjne, tani i łatwo dostępny sorbent. Dodatkowo odpad powstający w wyniku odsiarczania spalin- 
gips (reakcja 1) jest produktem użytecznym, który jest wykorzystywany w budownictwie.

$$
\mathrm{Ca}(\mathrm{OH})_{2}+\mathrm{SO}_{2}+\mathrm{H}_{2} \mathrm{O}+1 / 2 \mathrm{O}_{2} \rightarrow \mathrm{CaSO}_{4} * 2 \mathrm{H}_{2} \mathrm{O}
$$

Gips syntetyczny powstający w mokrej metodzie odsiarczania spalin może z powodzeniem zastąpić gips naturalny. W Polsce w roku 2015 gips syntetyczny był produkowany w trzynastu elektrowniach: Bełchatów, Dolna Odra, Opole, Jaworzno III, Łaziska, Konin, Pątnów I, Pątnów II, Połaniec, Kozienice, Ostrołęka, Rybnik, Siekierki [4]. Pierwszą instalację produkującą syntetyczny gips była instalacja w Bełchatowie uruchomiona w roku 1994. Jej aktualna zdolność produkcyjna wynosi około 1300 tys. t/rok. Kolejne były instalacje w elektrowniach Jaworzno III i Opole w wydajności odpowiednio 200 tys. i 350 tys. ton. Łączna zdolność produkcyjna wszystkich polskich instalacji do produkcji gipsu syntetycznego w roku 2013szacowana był na 2,9 mln ton. Na tle produkcji gipsu naturalnego produkcja gipsu syntetycznego jest o ponad 2,5 razy większa. W roku 2013 udział gips syntetycznego w całkowitej produkcji gipsu w Polsce wynosił około $72 \%$. Praktycznie cała ilość gipsu wytwarzanego przez elektrownie jest sprzedawana firmom produkującym gips. Otrzymywany gips syntetyczny może być wykorzystywany do produkcji płyt gipsowo-kartonowych [4]. Konieczność spełnienia coraz ostrzejszych norm dotyczących emisji $\mathrm{SO}_{2}$ do atmosfery przez elektrownie, oraz budowa czterech nowych bloków węglowych (2xOpole, Jaworzno i Kozienice), wyposażonych w instalację mokrego odsiarczania spalin spowoduje wzrost produkcji gipsu syntetycznego w Polsce. Szlugaj i Naworyta [4] szacują, że do roku 2020 produkcja gipsu syntetycznego wzrośnie do poziomu ponad $4 \mathrm{mln} \mathrm{t}$.

Szacuje się, że całkowita światowa emisja rtęci do atmosfery wynosi od 5000 do 6000 t/rok, z czego około 2000-3000 jest spowodowane działalnością człowieka. Największym emitorem rtęci do atmosfery są procesy spalania węgla w elektrowniach i elektrociepłowniach. Emisja antropogeniczna rtęci do atmosfery w Polsce wynosi około 10t/rok [5]. Polskie węgle kamienne zawierają średnio około $80 \mathrm{ng} / \mathrm{g}$ [6].Rtęć zawarta w węglu w wyniku spalania paliwa jest uwalniana $\mathrm{z}$ niego $\mathrm{w}$ ponad $99 \% \mathrm{w}$ postaci gazowej. Początkowo w temperaturach procesu spalania cała rtęci występuje jako rtęć elementarna $\mathrm{Hg}^{0}$. W miarę ochładzania się spalin następuje utlenienie par rtęci $\mathrm{Hg}^{0}$ do rtęci dwuwartościowej $\mathrm{Hg}^{2+}$. Ilość utlenionej rtęci $\mathrm{Hg}^{0}$ jest różna w zależności od rodzaju spalanego węgla, jego składu, rodzaju paleniska i sposobu prowadzenia procesu spalania i waha się od 10 do 90\% [7]. Rtęć elementarna jest trudno rozpuszczalna w wodzie i emitowana do atmosfery jest transportowana na dalekie odległości. Natomiast rtęć dwuwartościowa łączy się z innymi składnikami spalin tj.: $\mathrm{SO}_{2}, \mathrm{Cl}_{2}$, $\mathrm{O}_{2}$ tworząc gazowe związki tj.: $\mathrm{HgO}, \mathrm{HgCl}_{2}, \mathrm{Hg}_{2} \mathrm{Cl}_{2}, \mathrm{HgSO}_{4}$. Część utlenionej rtęci $\mathrm{Hg}^{2+}$ jest adsorbowana na formującym się popiele lotnym tworząc na nim związki stałe. Rtęć dwuwartościowa jest łatwo rozpuszczalna w wodzie, co po- 
woduje że może być łatwo wymywana ze spalin w instalacji mokrego odsiarczania spalin, przechodząc do odcieku z instalacji i do stałego produktu, czyli gipsu syntetycznego [8]. Dotychczas niewiele jest danych dotyczących zawartości rtęci w gipsie syntetycznym, będącym produktem IOSu. Przeprowadzono badania zawartości rtęci w gipsie naturalnym i syntetycznym, z których wynika, że średnia zawartość rtęci w gipsie naturalnym to $30 \mathrm{ng} / \mathrm{g}$, a w gipsie syntetycznym to około 100 ng/g [9]. Inne badania [9] porównują zawartość rtęci w płytach gipsowo-kartonowych produkowanych w Chinach i USA. Chińskie płyty zawierały od $190 \mathrm{ng} / \mathrm{g}$ rtęci do $562 \mathrm{ng} / \mathrm{g}$, natomiast płyty amerykańskie od 67 do $2080 \mathrm{ng} / \mathrm{g}$. W pracy [10] przedstawiono porównanie zawartości rtęci w gipsie naturalnym i syntetycznym. Dla gipsu naturalnego średnia zawartość rtęci wynosiła $39 \mathrm{ng} / \mathrm{g}$, natomiast dla syntetycznego było to $281 \mathrm{ng} / \mathrm{g}$. Opracowanie [11] zawiera wyniki badań zawartości rtęci w płytach gipsowo-kartonowych produkowanych z gipsu syntetycznego w różnych warunkach. Wyniki te pokazują, że zawartość rtęci wynosi od 70 do $950 \mathrm{ng} / \mathrm{g}$.

\section{Metodyka badań}

\subsection{Spektrometr do pomiaru zawartości rtęci}

Do badań zawartości rtęci w materiałach budowlanych wykorzystano spektrometr firmy Lumex RA-915+ z przystawką RP-91C (rys. 2). Analizator wykorzystuje technologię efektu Zeemana (Zeeman Atomic Absorption Spectrometry with High Frequency Modulated Light Polarization (ZAAS-HFM)), który pozwala na rezygnację z konieczności akumulowania rtęci na złotym sorbencie (rys. 2).

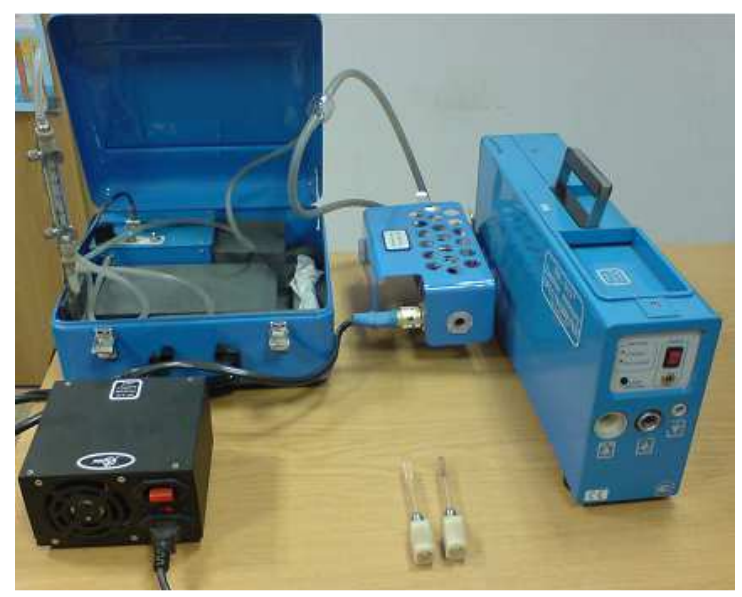

Rys. 2. Spektrometr RA-915+ z przystawką RP-91C

Fig. 2. Spectrometer RA-915 + with adapter RP-91C - mercury measurement setup 
Wyniki pomiaru stężenia par rtęci są podawane online w zakresie stężeń od 0,002 do $20 \mu \mathrm{g} / \mathrm{m} 3$, dla kuwety wielodrożnej. Do pomiaru zawartości rtęci w ciałach stałych konieczne jest dołączenie do analizatora przystawki pirolitycznej RP-91C. W przystawce pirolitycznej następuje rozkład i odparowanie par rtęci z związków zawierających rtęć. Spaliny zawierające pary rtęci są transportowane za pomocą gazu nośnego do kuwety pomiarowej, gdzie następuje ich oznaczenie.

\subsection{Stanowisko do badań emisji rtęci z płyt gipsowo-kartonowych}

Do badań emisji rtęci z płyt gipsowo-kartonowych wykorzystano stanowisko pieca poziomego (rys. 3). Pomiar polegał na umieszczeniu w piecu kawałka płyty gipsowo-kartonowej o wymiarach $1 \times 1 \times 1 \mathrm{~cm}$, w piecu poziomym ogrzewanym grzałkami elektrycznymi. Próbkę umieszczono w zimnym piecu, wewnątrz próbki znajdowała się na termopara typu $\mathrm{K}$, mierząca cały czas zmianę temperatury próbki. Do pieca podawano gaz nośny, którym było powietrze w ilości 6 l/min. W drugim końcu pieca umieszczono króciec pomiarowy, który podpięto do spektrometru Lumex w celu rejestracji uwalnianych par rtęci. Piec był nagrzewany od temperatury około $20^{\circ} \mathrm{C}$ do temperatury $500^{\circ} \mathrm{C}, \mathrm{z}$ ustaloną szybkością nagrzewania $10^{\circ} \mathrm{C} / \mathrm{min}$. Podczas całego testu rejestrowane były zmiany temperatury próbki i par rtęci.

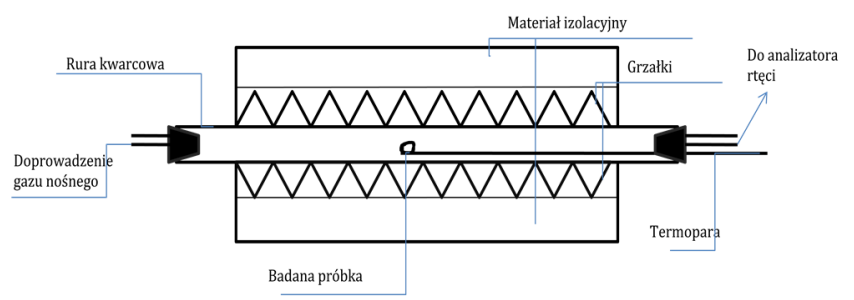

Rys. 3. Stanowisko pieca poziomego

Fig. 3. Scheme of horizontal furnace

\section{Wyniki badań}

Do badań zawartości rtęci wykorzystano cztery płyty gipsowo-kartonowe zakupiono w sklepach budowlanych na terenie Częstochowy. Wszystkie płyty były wyprodukowane w okresie od marca do listopada 2015 roku:

- płyta szara gipsowo kartonowa (GKB) o wymiarach 120×90 cm - próbka GK1, - płyta szara gipsowo-kartonowa (GKB) o wymiarach 90×60 cm - próbka GK2, - płyta szara gipsowo-kartonowa (GKB) o wymiarach 90×60 cm - próbka GK3, - płyta zielona o zwiększonej odporności na wilgoć (GKBI) gipsowo-kartonowa o wymiarach 90×60 cm - próbka GK4.

Z płyt o wymiarach $90 \times 60 \mathrm{~cm}$ pobrano do badań 9 próbek, a z płyty o wymiarach $120 \times 90$ - 13 próbek. Dla każdej próbki wykonano przynajmniej 10 powtórzeń. 
Wyniki badań zawartość rtęci dla płyt gipsowo-kartonowych przedstawiono w tabeli 1. Dla próbki GK1 średnia zawartość rtęci wynosiła około 311 ng/g, przy odchyleniu standardowym wynoszącym 11,4. Próbka GK2 miała średnią zawartość rtęci na poziomie $460 \mathrm{ng} / \mathrm{g}$, w tym przypadku odchylenie standardowe było większe i wynosiło około 37 . W przypadku próbki GK3 średnia zawartość rtęci wynosiła $265 \mathrm{ng} / \mathrm{g}$, dla tej próbki odchylenie standardowe było największe i wynosiło 45,1. Dla próbki GK4 średnia zawartość rtęci była najmniejsza i wynosiła około $227 \mathrm{ng} / \mathrm{g}$, przy odchyleniu standardowym 23,1 .

Tabela 1. Zawartość rtęci w płytach gipsowo-kartonowych

Table 1 . Mercury content in wallboard

\begin{tabular}{|c|c|c|c|c|}
\hline $\begin{array}{c}\text { Nazwa } \\
\text { próbki }\end{array}$ & $\begin{array}{c}\text { Hg } \\
\text { Minimum } \\
{[\mathbf{n g} / \mathbf{g}]}\end{array}$ & $\begin{array}{c}\text { Hg } \\
\text { Maksimum } \\
{[\mathbf{n g} / \mathbf{g}]}\end{array}$ & $\begin{array}{c}\text { Hg } \\
\text { średnia } \\
{[\mathbf{n g} / \mathbf{g}]}\end{array}$ & $\begin{array}{c}\text { Odchylenie } \\
\text { standardowe }\end{array}$ \\
\hline GK1 & 300 & 335,8 & 311,1 & 11,4 \\
\hline GK2 & 402,7 & 540 & 458,6 & 36,8 \\
\hline GK3 & 228,7 & 377 & 265,4 & 45,1 \\
\hline GK4 & 194,7 & 277,3 & 227,1 & 23,1 \\
\hline
\end{tabular}

Do badań zawartości rtęci gipsie budowlanym (tab. 2) wybrano dwie próbki gipsu budowlanego zakupionego w sklepach budowlanych w Częstochowie. Zawartość rtęci w próbce Gips 1 wynosiła średnio około $57 \mathrm{ng} / \mathrm{g}$, przy odchyleniu standardowym wynoszącym 2,1. Dla drugiej próbki Gips 2 średnia zawartość rtęci była dużo wyższa i wynosiła ponad $305 \mathrm{ng} / \mathrm{g}$, przy odchyleniu standardowym wynoszącym 6,4 .

Tabela 2. Zawartość rtęci w gipsie

Table 2. Mercury content in gypsum

\begin{tabular}{|c|c|c|c|c|}
\hline $\begin{array}{c}\text { Nazwa } \\
\text { próbki }\end{array}$ & $\begin{array}{c}\text { Hg } \\
\text { Minimum } \\
{[\mathbf{n g} / \mathbf{g}]}\end{array}$ & $\begin{array}{c}\text { Hg } \\
\text { Maksimum } \\
{[\mathbf{n g} / \mathbf{g}]}\end{array}$ & $\begin{array}{c}\text { Hg } \\
\text { średnia } \\
{[\mathbf{n g} / \mathbf{g}]}\end{array}$ & $\begin{array}{c}\text { Odchylenie } \\
\text { standardowe }\end{array}$ \\
\hline Gips 1 & 55 & 59 & 57,3 & 2,1 \\
\hline Gips 2 & 299 & 313 & 305,3 & 6,4 \\
\hline
\end{tabular}

Badania nagrzewania płyty gipsowo-kartonowej przeprowadzono dla próbki GK1 (rys. 4). Próbka była nagrzewana od około $20^{\circ} \mathrm{C}$ do $500^{\circ} \mathrm{C}$. Początek procesu uwalniania rtęci z próbki zaobserwowano w temperaturze około $150^{\circ} \mathrm{C}$, a pierwszy maksymalny pik w temperaturze około $190^{\circ} \mathrm{C}$, maksimum drugiego piku zaobserwowano $\mathrm{w}$ temperaturze $270^{\circ} \mathrm{C}$. Uzyskane wyniki odpowiadają temperaturą rozpadu $\mathrm{HgS}$, który powstaje w wyniku reakcji par rtęci z siarką obecną w spalinach w adsorberze mokrej instalacji odsiarczania spalin. 


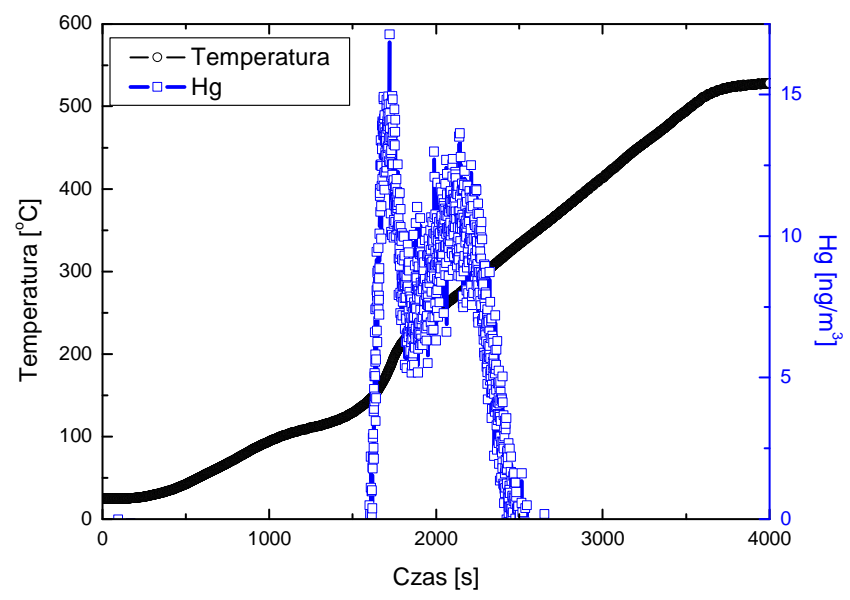

Rys. 4. Emisja rtęci podczas nagrzewania płyty gipsowokartonowej

Fig. 4. Emission of mercury during heating of wallboard

\section{Wnioski}

Na podstawie przeprowadzonych badań można zauważyć, że zawartość rtęci w płytach gipsowo-kartonowych jest bardzo wysoka i waha się od 227 do około $458 \mathrm{ng} / \mathrm{g}$. Rodzaj płyt GKB czy GKBI nie ma większego znaczenia jeśli chodzi o zawartość rtęci, chociaż zawartość rtęci w płycie GKBI (GK4) była mniejsza, aniżeli w pozostałych płytach GKB. Przeliczając to na masę jednej płyty, to zawartość rtęci w płytach wynoszą od 0,98 do $2,7 \mathrm{ng} \mathrm{Hg}$ na jedną płytę, przy założeniu ciężaru płyt na poziomie $8 \mathrm{~kg} / \mathrm{m}^{2}$. Zawartość rtęci w gipsie jest zależna od jego pochodzenia. Na podstawie danych literaturowych można stwierdzić, że Gips1 jest to prawdopodobnie gips naturalny, gdyż zawartość w nim rtęci jest stosunkowo niewielka ( $57 \mathrm{ng} / \mathrm{g}$ ), natomiast Gips 2 jest to prawdopodobnie gips syntetyczny o znacznie wyższej zawartości rtęci - $305 \mathrm{ng} / \mathrm{g}$. Badania uwalniania rtęci z płyt gipsowo-kartonowych pokazały, że rtęć jest w nich związana głównie w postaci $\mathrm{HgS}$, który powstaje w wyniku reakcji $\mathrm{w}$ adsorberze mokrej instalacji odsiarczania spalin.

\section{Literatura}

[1] Tomeczek J., Gradoń B., Rozpondek M.: Redukcja emisji zanieczyszczeń z procesów konwersji paliw i odpadów, Wydawnictwo Politechniki Śląskiej, Gliwice 2009.

[2] Kuropka J.: Technologie oczyszczania gazów z dwutlenku siarki i tlenków azot, Oficyna Wydawnicza Politechniki Wrocławskiej, Wrocław 2012.

[3] Grudziński Z.: Fakty: Węgiel - Energetyka w Polsce, Instytut GSMiE PAN - Kraków 2015. 
[4] Szlugaj J., Naworyta W.: Analiza zmian podaży gipsu w Polsce w świetle rozwoju odsiarczania spalin w elektrowniach konwencjonalnych, Gospodarka Surowcami Mineralnymi - Mineral Resources Management, vol. 31, no. 2, pp. 93-108.

[5] United Nations Environmental Programme, Global Mercury Assessment, UNEP Chemicals, Geneva, 2013.

[6] Wichliński M., Kobyłecki R., Bis Z., The investigation of the mercury contents in Polish coal samples, Archives of Environmental Protection vol. 39, no. 2, 2013.

[7] Galbreath KC, Zygarlicke CJ. Mercury transformation in coal combustion flue gas. Fuel Processing Technology 2000; 65-66, pp. 289-310.

[8] Senior C.L., Sarofim A.F., Zeng T.F., Helble J.J., Mamani-Paco R., Gas-phase transformations of mercury in coal-fired power plants, Fuel Processing Technology 63, 2000 pp. 197-213.

[9] https://www.pharosproject.net/blog/show/40/mercury-contamination-drywall \{dostęp 28.05.2016 r.\}.

[10] Coal Combustion Residual Beneficial Use Evaluation: Fly Ash Concrete and FGD Gypsum Wallboard, United States Environmental Protection Agency, 2014.

[11] Sanderson J., Blythe G.M., Richardson M.: Fate of Mercury in Synthetic Gypsum Used for Wallboard Production, National Energy Technology Laboratory, U.S. Department of Energy, 2008.

\section{RESEARCH INTO MERCURY CONTENT IN SELECTED CONSTRUCTION MATERIALS}

\section{S u m m a ry}

The article presents the results of the mercury content of wallboards used in construction. The aim of the study is to draw attention to the problem which is a very high concentration of mercury in the boards, which are commonly used in construction. Wallboard are currently the most popular material for finishing rooms in the so-called. drywall. Gypsum contained in these boards comes mainly from the installation of wet flue-desulphurisation (FGD) and as such is burdened with a load of mercury, which has been removed from the gas stream in FGD. The study used 4 wallboard, different manufacturers, purchased in construction stores in Częstochowia, and two samples of gypsum. The results of the research carried out with mercury content, using a spectrometer Lumex RA-915 + with an attachment pyrolitic-RA-91C. The results obtained show that the average mercury content in the plates is very high, roughly from 227 to $458 \mathrm{ng} / \mathrm{g}$. The mercury content in the building gypsum was roughly from 57 to $305 \mathrm{ng} / \mathrm{g}$. Also have been investigated by subjecting the wallboard to a temperature slice. Clipping plates heated at a constant rate while measuring the amount of mercury released. The results showed that the mercury emissions followed at temperatures of from 150 to $300^{\circ} \mathrm{C}$, the emission double maximum were at temperatures 190 and $270^{\circ} \mathrm{C}$. That release of mercury temperature indicates that mercury is contained in wallboards mainly as $\mathrm{HgS}$.

Keywords: wallboard, gypsum, construction, installation of wet flue gas desulphurization

DOI: $10.7862 / \mathrm{rb} .2016 .300$

Przestano do redakcji: $30.06 .2016 r$.

Przyjęto do druku: 20.12.2016 r. 